\title{
Inmigración e impacto en la infectología de recién nacidos
}

\author{
Giannina Izquierdo, Alejandra Reyes, Luis Delpiano, Marta Aravena, Fernanda Cofré, \\ Mariluz Hernández, Yenis Labraña y Alejandra Sandoval \\ Integrantes Comité Consultivo de Infecciones Neonatales. Sociedad Chilena de Infectología
}

Recibido: 26 de julio de 2017 Correspondencia a: Giannina Izquierdo Copiz gianninai@yahoo.es

\section{Immigration and impact on infectious diseases of the newborn}

Over the past few years immigration has become an important issue in Chile. Particular attention should be paid in foreign pregnant mothers. Infectious diseases screening in this group greatly reduce the risk of transmission to the fetus with appropriate therapy.

Key words: Immigration, newborn, infectious disease, pregnant women.

Palabras clave: Inmigración, recién nacido, enfermedad infecciosa, mujer embarazada.
E $\mathrm{n}$ la historia de la humanidad, los inmigrantes han tenido un rol fundamental, no tan sólo en el desarrollo de los pueblos, sino también en la transmisión de enfermedades infecciosas; son ejemplos de esto las plagas descritas en el antiguo testamento, la viruela introducida en América en el año 1493, la gran mortalidad causada en Europa por la influenza española en 1918, hasta la introducción del VIH desde África a nuestro continente ${ }^{1}$.

La movilización de personas más allá de sus fronteras trae consigo grandes impactos para el país que los recibe, y en el ámbito de la salud éste puede experimentar cambios epidemiológicos significativos con aparición de enfermedades emergentes como el virus Zika, aumento de la incidencia de enfermedades ya existentes: hepatitis B (VHB), VIH, hepatitis C (VHC) y tuberculosis, o surgimiento de enfermedades que son desconocidas para el personal de salud: virus linfotrópico humano de células T tipo 1 (HTLV-I) y anemia de células falciformes, como ejemplos. Todos estos cambios se traducen en la necesidad de realizar modificaciones en las políticas de salud pública del país.

Según el Ministerio de Desarrollo Social (Encuesta de Caracterización Económica Nacional, CASEN 2015) el porcentaje de inmigrantes ha ido en un franco aumento en los últimos años. Se describe en Chile aumento desde $1 \%$ (154.643) de inmigrantes en el año 2006 a $2,7 \%$ (465.319) en el 2015. Un 30\% la población inmigrante es de origen peruano, pero destaca en los últimos años (2013-2015) el aumento de población proveniente de México y la región del Caribe ${ }^{2}$. La población haitiana ha tenido un claro crecimiento; así, mientras durante el año 2013 ingresó al país un total de 2.428 haitianos (ya fuese en condición de turistas o residentes), para el año 2015 esta cifra ascendió a un total de 9.477. Se trata del mayor aumento relativo de los últimos tres años (por amplia diferencia), en comparación a los principales flujos migratorios hacia Chile, seguido en segundo lugar por un aumento también sostenido de la inmigración peruana, observada principalmente entre los años 2013 y $2014^{3}$.

El $69 \%$ de la población inmigrante se encuentra en la Región Metropolitana concentrada en algunas áreas o servicios de salud, como norte, centro y sur de Santiago. Un $51,9 \%$ son mujeres y $67,3 \%$ de ellas están en edad fértil $^{2}$. Por este motivo se ha visto un aumento significativo de mujeres embarazadas extranjeras atendiendo sus partos en las maternidades del sistema de salud público, generando un gran desafío al personal debido a las dificultades en su atención, ya sea por el idioma, diferencias socio-culturales y de salud. El Hospital San José (comuna de Independencia), posee la maternidad que más partos atiende en el país. Sólo en 2016 vio nacer 7.544 recién nacidos $(\mathrm{RN})$; de ellos, $25 \%$ fue hijo de una madre extranjera. Por otra parte, en el sector sur de Santiago, el Complejo Asistencial Barros Luco Trudeau también acoge a una significativa población de mujeres embarazadas inmigrantes. En un análisis local, sobre la nacionalidad de las mujeres hospitalizadas en la maternidad, se observó que $18 \%$ de los partos del primer semestre de 2017 (1.903 partos) correspondieron a mujeres extranjeras, siendo $58,9 \%$ haitianas.

En el Hospital Clínico San Borja Arriarán del Servicio de Salud Central, 41\% (1.714) de los partos el 2015 fueron de madres inmigrantes, cifra que subió a 50\% (2.131) de los nacimientos el 2016.

Este análisis y el sostenido aumento de madres inmigrantes hace que el Comité de Infecciones Neonatales de la Sociedad Chilena de Infectología manifieste su preocupación por la salud de los RN, debido al desconocimiento de algunas co-morbilidades de las madres extranjeras que vienen a dar a luz a nuestro país. La falta de registro y notificación de enfermedades infecciosas 
transmisibles hace que las prevalencias sean subestimadas en los países de origen. Según datos del Banco Mundial $2015^{4}$, las diferencias en indicadores de salud de países latinoamericanos es, en ocasiones, abismante. La mortalidad infantil en Haití, según cifras oficiales, es cercana a 52 por 1.000 RNV y en Perú de 13 por 1.000 RNV, casi el doble de lo descrito en Chile (7 por 1.000 RNV). Cerca de 130.000 personas tienen infección por VIH en Haití, con una prevalencia de $1,7 \%(1,4-2,1 \%)^{5}$ de la población; cinco veces la prevalencia de Chile $(0,3 \%)$.

Según el Departamento de Epidemiología, División de Planificación Sanitaria del Ministerio de Salud, existe $5,5 \%$ de las personas extranjeras con infección por VIH en nuestro país. Si se analiza por Servicio de Salud, al 30 de abril del presente año, $20 \%$ de las personas con infección por VIH son extranjeras en el área norte, $12,5 \%$ en el área centro y $14,3 \%$ en el sur. Se ha observado también un incremento de las mujeres embarazadas extranjeras en control por estar con infección por VIH en las diversas áreas de salud, alcanzando porcentajes de $88 \%$ en el área norte, $69 \%$ centro y $50 \%$ sur $^{6}$.

Por otra parte, sabemos que Chile es un país de baja endemia de $\mathrm{VHB}(<1 \%)^{7}$ y que los países de mayor flujo migratorio hacia Chile (Latinoamérica y el Caribe) tienen endemia intermedia y alta $^{8}$. En Haití se estima que la prevalencia de infección por VHB es de 5,6\% ${ }^{9}$. Actualmente no existe normativa acerca del tamizaje de VHB a todas las mujeres embarazadas y debido al contexto actual del país y de nuestras maternidades, debemos plantearnos cambiar el estudio habitual, para lograr tomar medidas eficaces que prevengan la transmisión vertical de esta patología.

La transmisión de VHB al RN ocurre fundamentalmente en el parto por la exposición a fluidos maternos, por lo que es de suma importancia la inmunoprofilaxis en las primeras $12 \mathrm{~h}$ de vida. Se conoce que el riesgo de una infección crónica es inversamente proporcional al momento de la adquisición del virus. Aquella madre con HBsAg y HBeAg (+) tiene 70 a $90 \%$ de probabilidad de infectar a su RN y de éstos, 90\% evolucionarán hacia enfermedad crónica en un corto plazo. Por otra parte, las madres sólo con HBsAg $(+)$ infectan a 5 a $20 \%$ de sus hijos $^{9}$. Con la inmunoprofilaxis, el riesgo de infección crónica disminuye a $10-15 \%$ en madres con HBeAg $(+)$ y a menos de $1 \%$ en aquellas sólo con HBsAg $(+)^{10}$.

La inmunoprofilaxis de VHB es una emergencia y consiste en la administración de la vacuna pediátrica de VHB $(10 \mu \mathrm{g}$ IM o $0,5 \mathrm{ml}$ de la vacuna adulto de $20 \mu \mathrm{g})$ y la inmunoglobulina específica anti HB (HBIG) por vía IM, antes de las primeras $12 \mathrm{~h}$ de vida, en el mismo tiempo, en sitios distintos, independiente del peso. $\mathrm{Su}$ postergación ha demostrado franca disminución de la efectividad de la medida ${ }^{11}$.
El conocimiento previo al parto del estatus de VHB de la mujer embarazada permitiría coordinar la obtención de la inmunoprofilaxis con la SEREMI de salud local y así poder contar con la vacuna e inmunoglobulina antes del plazo establecido, sin demoras. Por esta razón y dado el contexto epidemiológico actual, en nuestras maternidades sería de vital importancia realizar HBsAg a todas las mujeres embarazadas, pero especialmente a las gestantes provenientes de países con alta incidencia y pacientes chilenas con factores de riesgo. A modo de plan piloto, en la maternidad del Complejo Asistencial Barros Luco Trudeau, a contar del 1 de julio del presente año comenzó a realizar tamizaje con $\mathrm{HbsAg}$ a todas la madres extranjeras en el preparto, con la finalidad de establecer la real magnitud del problema en este grupo de pacientes.

Además, existe otra infección en la futura madre que requiere de una intervención en el momento del parto, menos conocida en nuestro medio, y que corresponde al HTLV-I. Este agente es un virus de la familia Retroviridae y está relacionado con linfoma/leucemia de células $\mathrm{T}$; $\mathrm{y}$ paraparesia espástica tropical en el adulto.

Existe endemia considerable en Japón, países del Caribe y Sud América. En Perú la prevalencia de infección es de 1 a 7\%, dato tomado de donantes de sangre, gestantes y trabajadoras sexuales ${ }^{12}$. En Chile se conoce una prevalencia de $0,5 \%$ en bancos de sangre ${ }^{13}$. La transmisión vertical ocurre principalmente por lactancia materna (LM) prolongada: $4 \%$ en LM menor de 6 meses y $33 \%$ en LM de más de 2 años. En muy raras ocasiones se transmite durante el embarazo o el parto (a diferencia del VIH). La infección en la madre contraindica la LM, siendo la única forma de prevención en el RN. Volviendo a lo mismo y conociendo la incidencia en países vecinos, debería considerarse, al menos realizar el tamizaje en la población migrante de países con alta prevalencia, debido a que conocer el estatus materno genera un cambio significativo de la conducta del equipo de salud.

En nuestro país, a toda mujer embarazada que ingresa a control prenatal en el sistema público, independiente de su origen, se le solicita:

- Serología de VIH al inicio y entre las 32 y 34 semanas de embarazo se repite este test en aquellas mujeres con factores de riesgo, si bien en algunos Servicios de Salud se realiza a todas las mujeres, de manera independiente de los factores de riesgo, un segundo test para VIH cercano al parto ${ }^{14}$.

- Estudio de sífilis con tres VDRL durante la gestación y un VDRL en el parto.

- Desde el 2014, detección de Chagas en zonas endémicas: desde la Región de Arica-Parinacota hasta la Región de O’Higgins, incluida la Región Metropolitana. 
- En el caso de las madres seropositivas para VIH, el estudio se amplía a la detección de infección por VHB, VHC, Toxoplasma gondii y tuberculosis.

En consecuencia, en la gran mayoría de las mujeres extranjeras embarazadas desconocemos cuál es la seroprevalencia de enfermedades infecciosas importantes y que generan una carga de enfermedad, como la VHB y HTLV-1.

Por todo lo anteriormente expuesto, como Comité de Infecciones Neonatales, recomendamos incorporar a las políticas de salud pública de nuestro país el tamizaje para VHB y HTLV1 en mujeres gestantes inmigrantes de países con alta incidencia de estas infecciones, como también en chilenas con factores de riesgo. Esta medida costo efectiva, constituiría un avance significativo en el cuidado de la salud de estos grupos vulnerables de mujeres embarazadas y sus RN, la cual necesariamente impactará en la salud pública de nuestro país y permitirá abordar la salud de la población inmigrante en forma responsable e integral.

El Comité de Infecciones Neonatales está abierto a colaborar y desarrollar un trabajo conjunto con el Ministerio de Salud, en establecer guías o protocolos de manejo, que permitan llevar a cabo lo solicitado.

\section{Resumen}

El fenómeno migratorio en Chile ha aumentado en forma exponencial en los últimos años y con ello las mujeres embarazadas extranjeras en las maternidades de nuestro país. El conocer el estado de salud y el tamizaje de enfermedades infecciosas en la madre, permitiría tomar conductas preventivas de gran impacto en el recién nacido.

\section{Referencias bibliográficas}

1.- Barnett E, Walker P. Role of immigrants and migrants in emerging infectious diseases. Med Clin N Am 92; 2008: 1447-58.

2.- Encuesta de Caracterización Socioeconómica Nacional CASEN 2015. 21 de diciembre de 2016. http://observatorio.ministeriodesarrollo social.gob.cl/casen-multidimensional/casen/ docs/CASEN_2015_INMIGRANTES 21122016_EXTENDIDA_publicada.pdf.

3.- Boletín Informativo Departamento de Extranjería e Inmigración $\mathrm{N}^{\circ} 1$ Migración Haitiana en Chile. http://www.extranjeria.gob. cl/media/2016/09/boletin-1.pdf.

4.- Organización Mundial de la Salud 2015. http:// www.who.int/countries

5.- ONUSIDA países http://www.unaids.org/es/ regionscountries/countries

6.- Encuesta de los pacientes VIH en control por Servicio de Salud en el primer semestre del 2017 (hasta 30/06/2017).

7.- Vigilancia de laboratorio de hepatitis B. Boletín Instituto Salud Pública Vol 2, № 8, Mayo 2012. www.ispch.cl/sites/default/files/Boletín\%20 hepatitis\%20B\%20ISP.pdf

8.- Boletín hepatitis B http://www.who.int/ mediacentre/factsheets/fs204/es/.

9.- American Academy of Pediatrics. Hepatitis B. In: Kimberlin DW, Brady MT, Jackson MA, Long SS, eds. Red Book: 2015 Report of the Committee on Infectious Diseases. 30th ed. Elk Grove Village, IL: American Academy of Pediatrics 2015; 400-23.

10.- Valdés E, Sepúlveda A, Candia P, Lattes K. Hepatitis aguda viral durante el embarazo. Rev
Chilena Infectol 2010; 27 (6): 505-12. https:// dx.doi.org/10.4067/S0716-10182010000700003

11.- Guía clínica: Manejo y tratamiento de la infección crónica por virus de la hepatitis B (VHB), 2013: http://web.minsal.cl/AUGE_ GUIAS_CLINICAS

12.- Alarcón J, Romaní F, Montano S, Zunt J. Vertical transmission of HTLV-1 in Peru. Rev Peruana Med Exp Salud Pública 2011; 28 (1): 101-8. https://dx.doi.org/10.1590/S172646342011000100016

13.- Boletín Instituto de Salud Pública de Chile HTLV I-II. 2010-2014. 2015; Vol 5 (8), http:// www.ispch.cl/sites/default/files/BOLETIN\%20 HTLV.pdf

14.- Norma Conjunta de Transmisión Vertical del VIH y la Sífilis. Rev Chilena Infectol 2013; 30 (3): 259-302. 